\title{
STUDI PARAMETRIK \\ MORTAR GEOPOLIMER HYBRID ABU SAWIT (PALM OIL FUEL ASH/POFA)
}

\author{
Ramadhan Yanuari ${ }^{1}$, Muhammad Ikrammullah ${ }^{1}$, Dinda Septari ${ }^{1}$, \\ Miguel Felix Wijaya ${ }^{2}$ dan Monita Olivia ${ }^{3 *}$ \\ 1 Mahasiswa Program Sarjana / Jurusan Teknik Sipil / Fakultas Teknik / \\ Universitas Riau \\ 2 Alumni Program Sarjana / Jurusan Teknik Sipil / Fakultas Teknik / \\ Universitas Riau \\ 3 Dosen, Jurusan Teknik Sipil / Fakultas Teknik / Universitas Riau \\ *Penulis Korespondensi: monita.olivia@lecturer.unri.ac.id
}

\begin{abstract}
In this study, the Palm Oil Fuel Ash (POFA) was used as a raw material for making geopolymer mortars that uses a combination of sodium hydroxide $(\mathrm{NaOH})$ and sodium silicate $\left(\mathrm{Na}_{2} \mathrm{SiO}_{3}\right)$. The purpose of this study was to determine the effect of various parameters on the compressive strength of mortars. The parameters involved were namely modulus of activator ratio (Ms 1-3), the molarity of $\mathrm{NaOH}$ (10-16M), curing temperature $\left(28-110^{\circ} \mathrm{C}\right)$, type of POFA particle processing (oven-dried, passed the \#200 sieve, burned in a brick kiln, burned at $800^{\circ} \mathrm{C}$ ), rest periods of 3 and 5 days. Based on the parametric study, it was found the optimum mixture with the highest compressive strength consisted of NaOH 14M, Ms ratio of 2.5, curing temperature of 100OC, a rest period of 5 days, particles sieved using \#200 sieve and had 15\% PCC content.
\end{abstract}

Keywords: Palm Oil Fuel Ash (POFA), compressive strength, geopolymer cement, parametric study, portland cement

\section{PENDAHULUAN}

Berdasarkan Laporan Tahunan PT Semen Indonesia, Kapasitas produksi semen di Indonesia mencapai 53 juta ton pada awal tahun 2018 [1]. Produksi semen diperkirakan akan terus mengalami peningkatan karena kebutuhan industri konstruksi dalam pembangunan infrastruktur di berbagai wilayah di Indonesia. Semen Portland diproduksi menggunakan batu kapur sebagai bahan utama dari sumber daya alam yang tidak dapat diperbaharui dan secara perlahan akan habis jika digunakan terus-menerus. Selain itu, dampak lain akibat produksi semen Portland adalah meningkatnya gas emisi karbondiosida $\left(\mathrm{CO}^{2}\right)$ akibat dari pembakaran batu kapur (kalsinasi) pada suhu $1400-1450^{\circ} \mathrm{C}$. Industri semen menjadi salah satu penyumbang terbesar dalam sumber emisi polusi [2]. Oleh karena itu, seiring dengan meningkatnya penggunaan semen dalam konstruksi, maka akan semakin meningkat pemanasan global yang terjadi akibat emisi gas karbondioksida.

Semen geopolimer merupakan salah satu alternatif mengurangi penggunaan semen dari proses yang tidak ramah lingkungan dengan cara melakukan sintesis silika dan alumina dalam bahan utama geopolimer. Geopolimer adalah material dari reaksi polimerik silikat alumina anorganik dari bahan sumber dengan kandungan silika dan alumina yang tinggi, seperti fly ash (abu terbang), slag atau metakaolin [3]. Prinsip geopolimer adalah mereaksikan silika dan alumina dengan larutan alkali aktivator untuk menghasilkan pengikat seperti semen. Penelitian sebelumnya menunjukkan bahwa geopolimer memiliki daya tahan yang baik di lingkungan agresif [4].

Indonesia merupakan produsen minyak kelapa sawit (CPO) di dunia. luas lahan kelapa sawit di Indonesia mencapai 14.309.256 hektar 
dengan total produksi minyak sawit sebesar 41.667.011 ton pada tahun 2018 [5]. Sebagai salah satu penghasil minyak kelapa sawit (CPO) terbesar di Indonesia, Provinsi Riau memiliki luas perkebunan kelapa sawit (PKS) sebesar 2.103.176 hektar, 28,7 juta limbah cair per tahun dan 15,2 juta limbah padat per tahun. Limbah padat seperti cangkang sawit, inti sawit, dan tandan kosong dibakar dalam boiler untuk menghasilkan abu sawit atau Palm Oil Fuel Ash (POFA).

Pemanfaatan POFA dalam beton hingga saat ini masih belum maksimal dan belum banyak diaplikasikan dalam konstruksi. POFA dapat digunakan dalam campuran beton dengan kadar $10-30 \%$ sebagai bahan pozzolanik pengganti sebagian semen [6]. Penggunaan POFA dengan kadar di atas $80 \%$ dapat berupa material geopolimer diaktifkan dengan larutan aktivator. Hasil uji karakteristik kimia menggunakan $X R F$ menunjukkan bahwa abu sawit (POFA) adalah material pozzolanik yang cocok diubah melalui reaksi polimerisasi karena kandungan silika dan alumina cukup tinggi pada bahan tersebut [7]. Penelitian Olivia et al. [8] menghasilkan mortar geopolimer POFA dengan kuat tekan sedang (22,93 MPa). Pada penelitian tersebut, semen OPC digunakan untuk menghasilkan mortar geopolimer hybrid abu terbang (POFA) agar dapat dirawat pada suhu ruang. Mortar geopolimer hybrid POFA menggunakan semen Portland Composite Cement (PCC) belum pernah diteliti sebelumnya, padahal semen PCC lebih banyak ditemukan di pasaran. Pada penelitian ini akan dikaji studi parametrik mortar geopolimer hybrid POFA untuk menghasilkan komposisi optimum berdasarkan parameter $\mathrm{NaOH}, \mathrm{Ms}$ (rasio $\mathrm{NaOH} /$ sodium silikat) dan persentase semen PCC.

\section{TINJAUAN PUSTAKA}

\subsection{Mortar}

Mortar adalah campuran beberapa material meliputi semen, agregat halus dan air [9]. Fungsi mortar adalah untuk menambah lekatan pada bagian konstruksi tertentu lainnya. Ukuran mortar adalah kubus kecil dengan dimensi sisi 5x5x5 cm. Spesifikasi mortar dibagi menjadi empat tipe, yaitu tipe $\mathrm{M}$, tipe $\mathrm{S}$, tipe $\mathrm{N}$ dan tipe $\mathrm{O}$ sesuai dengan kekuatan tekan dan aplikasi masing-masing tipe di lingkungan tertentu [10].

\subsection{Semen Geopolimer}

Geopolimer menjadi pengikat alternatif bahan konstruksi untuk aplikasi tertentu yang berkelanjutan dan bersifat ramah lingkungan. Material yang ditemukan oleh Davidovits [11] tersebut dikenal sebagai geopolimer dan memiliki fungsi sebagai perekat alternatif pengganti semen Portland. Bahan dasar geopolimer berupa material alami atau limbah hasil sampingan industri yang diberi larutan alkali untuk mereaksikan unsur silika (Si) dan aluminium (Al). Semen geopolimer terbentuk berdasarkan hasil reaksi kimia dan bukan dari reaksi hidrasi seperti pada semen Portland. Oleh karena itu, jenis alkali aktivator yang digunakan harus sesuai dengan senyawa dalam bahan dasar dan memiliki komposisi tepat sehingga dapat membentuk bahan dengan struktur jaringan kuat dan tahan lama menggunakan reaksi polimerisasi.

Larutan aktivator untuk geopolimer dapat berupa natrium hidroksida $(\mathrm{NaOH})$, natrium sulfat $\left(\mathrm{Na}_{2} \mathrm{SO}_{4}\right)$, natrium silikat $\left(\mathrm{Na}_{2} \mathrm{SiO}_{3}\right)$, kalium hidroksida $(\mathrm{KOH})$ dan natrium karbonat $\left(\mathrm{Na}_{2} \mathrm{CO}_{3}\right)$. Campuran natrium hidroksida $(\mathrm{NaOH})$ dan natrium silikat $\left(\mathrm{Na}_{2} \mathrm{SiO}_{3}\right)$ lebih banyak digunakan karena dapat menghasilkan geopolimer dengan kuat tekan tinggi [12]. Penelitian Adam [13] menunjukkan bahwa alkali aktivator berupa campuran $\mathrm{NaOH}$ dan $\mathrm{Na}_{2} \mathrm{SiO}_{3}$ menghasilkan geopolimer dengan kekuatan terbaik. Fernandez-Jimenez [14] melaporkan bahwa kombinasi campuran $\mathrm{NaOH}$ dan $\mathrm{Na}_{2} \mathrm{SiO}_{3}$ yang tepat akan menghasilkan material geopolimer padat hampir tidak berpori dan memiliki ikatan kuat antara agregat dan matriks. Disamping itu sodium silikat pada geopolimer tidak hanya meningkatkan kuat tekan, tetapi juga berguna sebagai perekat tambahan untuk membentuk pasta geopolimer yang lebih solid [15].

\subsection{Abu Sawit (Palm Oil Fuel Ash)}

Luas perkebunan kelapa sawit terus meningkat setiap tahun. Setiap 1 hektar PKS dapat menghasilkan 1,5 ton limbah padat tandan kosong kelapa sawit (TKKS)/tahun kering atau 2,64 ton TKKS dengan kadar air 50\% [16]. Limbah padat PKS tersebut kemudian dibakar pada suhu $800-1000^{\circ} \mathrm{C}$ sebagai penghasil listrik dan tenaga uap pada pabrik kelapa sawit. Hasil pembakaran tersebut menghasilkan POFA (Palm Oil Fuel Ash) atau abu sawit.

Hasil analisis kimia di Laboratorium Teknik Kimia, Universitas Andalas untuk abu sawit yang berasal dari PT PKS GAS, Kandis, Riau menunjukkan kandungan kimia dari POFA adalah $\mathrm{SiO}_{2}, \mathrm{Al}_{2} \mathrm{O}_{3}$, dan $\mathrm{Fe}_{2} \mathrm{O}_{3}$ lebih dari $60 \%$. Menurut ASTM C-168 2005 [17], POFA tersebut termasuk dalam bahan pozzolan tipe $\mathrm{C}$ dan hasil ini telah memenuhi syarat sebagai pengganti 
semen. Bahan pozzolan merupakan material aktif yang dapat bereaksi dengan kapur bebas dan air membentuk material seperti semen yaitu kalsium silikat hidrat sehingga mortar yang dihasilkan lebih baik [7]. Pemanfaatan POFA sebagai pozzolan berpotensi menjadi pengganti semen dan dapat mengatasi masalah lingkungan, mengurangi lahan untuk pembuangan POFA dan mengurangi biaya konstruksi.

\subsection{Semen Portland}

Semen Portland merupakan material perekat dari kapur yang dicampur dengan air membentuk zat pengikat benda-benda padat serta membentuk satu kesatuan massa solid dan keras. Suatu semen jika diaduk dengan air kemudian ditambahkan pasir menjadi mortar semen, dan jika ditambah dengan agregar kasar akan menjadi beton. Unsur utama pembentuk semen Portland adalah kapur $(\mathrm{CaO})$, silika $\left(\mathrm{SiO}_{3}\right)$, aluminium $\left(\mathrm{Al}_{2} \mathrm{O}_{3}\right)$ magnesia $(\mathrm{MgO})$ dan alkali [18].

\subsection{Larutan Alkali Aktivator}

Aktivator yang digunakan pada pembuatan mortar dengan pasta semen geopolimer POFA adalah Sodium hidroksida $(\mathrm{NaOH})$ dan Sodium silikat $\left(\mathrm{Na}_{2} \mathrm{SiO}_{3}\right)$. Sodium silikat berfungsi sebagai katalis untuk meningkatkan kecepatan reaksi polimerik dan sebagai perekat antara material lain untuk memperkuat pasta mortar. Sedangkan, sodium hidroksida $(\mathrm{NaOH})$ berfungsi untuk mereaksikan silika dan alumina dari abu terbang sehingga dihasilkan ikatan polimerik yang kuat [19]. Berdasarkan hasil penelitian Hardjito et al. [20], larutan $\mathrm{NaOH}$ sebaiknya digunakan dengan konsentrasi sebesar 8-16M untuk mendapatkan kuat tekan beton yang lebih tinggi. Semakin tinggi konsentrasi $\mathrm{NaOH}$, akan semakin tinggi pula kuat tekan beton geopolimer.

\subsection{Superplasticizer}

Superplasticizer adalah bahan tambah untuk meningkatkan kemudahan dalam pengerjaan atau workabilitas campuran. Superplasticizer berguna agar mortar yang dihasilkan tidak mengalami pemisahan (segregasi/bleeding) dengan jumlah air besar dalam campuran [21]. Salah satu fungsi superplasticizer adalah memudahkan pekerjaan karena bersifat seperti pelumas dan tidak menambah air.

\subsection{Pengujian Kuat Tekan}

Berdasarkan SNI 03-6825-2002 [9], kuat tekan mortar adalah beban maksimum dengan satuan luas benda uji mortar berbentuk kubus dengan ukuran dan umur tertentu. Ukuran mortar umumnya adalah kubus kecil dengan dimensi sisi $5 \times 5 \times 5 \mathrm{~cm}$. Kuat tekan mortar dihitung dengan menggunakan rumus berikut:

$$
\sigma \mathrm{m}=\mathrm{P} / \mathrm{A}
$$

dengan:

$$
\begin{aligned}
& \sigma \mathrm{m}=\text { kuat tekan mortar }(\mathrm{MPa}) \\
& \mathrm{P}=\text { beban maksimum }(\mathrm{N}) \\
& \mathrm{A}=\text { luas penampang yang dibebani }\left(\mathrm{mm}^{2}\right)
\end{aligned}
$$

\section{METODOLOGI PENELITIAN}

\subsection{Bahan}

Bahan penyusun mortar menggunakan semen geopolimer abu sawit adalah Palm Oil Fuel Ash (POFA), agregat halus, larutan aktivator, superplasticizer dan air. POFA yang digunakan berasal dari Perkebunan Kelapa Sawit (PKS) Serikat Putra, Kabupaten Pelalawan, Provinsi Riau.

Tabel 1. Karakteristik Kimia POFA

\begin{tabular}{cc}
\hline Oksida & Massa (\%) \\
\hline $\mathrm{SiO}_{2}$ & 49,85 \\
\hline $\mathrm{Al}_{2} \mathrm{O}_{3}$ & 10,40 \\
\hline $\mathrm{Fe}_{2} \mathrm{O}_{3}$ & 0,79 \\
\hline $\mathrm{CaO}$ & 7,18 \\
\hline $\mathrm{MgO}$ & 4,69 \\
\hline $\mathrm{Na}_{2} \mathrm{O}$ & 0,05 \\
\hline $\mathrm{K}_{2} \mathrm{O}$ & 3,76 \\
\hline $\mathrm{P}_{2} \mathrm{O}_{5}$ & 5,60 \\
\hline $\mathrm{SO}_{3}$ & 0,77 \\
\hline $\mathrm{LOI}$ & 3,78 \\
\hline
\end{tabular}

Pada Tabel 1 dapat dilihat jumlah total kandungan $\mathrm{SiO}_{2}, \mathrm{Al}_{2} \mathrm{O}_{3}$ dan $\mathrm{Fe}_{2} \mathrm{O}_{3}$ POFA adalah 61,37\%. Hal ini menunjukkan bahwa POFA setara dengan material pozzolanik kelas $\mathrm{C}$ berdasarkan ASTM C-618 2005 [17]. Pengujian karakteristik kimia POFA dilakukan di Balai Riset dan Standardisasi Nasional, Padang.

Agregat halus atau pasir untuk penelitian berasal dari Teratak Buluh, Kampar. Agregat halus ukuran butirnya lebih kecil dari $4,75 \mathrm{~mm}$ dan lebih besar dari $0,075 \mathrm{~mm}$ berdasarkan SNI 03-1968-1990 [22]. Pengujian dilakukan di Laboratorium Bahan, Fakultas Teknik, Universitas Riau. Hasil uji karakteristik agregat halus menunjukkan bahwa modulus kehalusan pasir adalah 2,94, kadar air sekitar 2,20\%, berat jenis 2,20 , dan berat volume $1,72 \mathrm{gr} / \mathrm{cm}^{3}$.

Larutan alkali aktivator pada penelitian ini 
adalah kombinasi natrium silikat $\left(\mathrm{Na}_{2} \mathrm{SiO}_{3}\right)$ dan natrium hidroksida $(\mathrm{NaOH})$. Perbandingan antara natrium silikat dan natrium hidroksida atau modulus aktivator (Ms) digunakan dalam perencanaan campuran mortar.

Sodium hidroksida berbentuk padatan dilarutkan di dalam air sehingga menjadi larutan sesuai dengan molaritas yang diinginkan. Sedangkan, sodium silikat berbentuk larutan memiliki mol rasio 2,26 yang terdiri dari senyawa solid $\mathrm{SiO}_{2}$ dan $\mathrm{Na}_{2} \mathrm{O}$ sebanyak $31,75 \%$ dan $14,51 \%$ serta total sebanyak $46,26 \%$. Pengujian karakteristik sodium silikat dari PT. Sinar Sakti Kimia, Jawa Tengah dapat dilihat pada Tabel 2.

Superplasticizer berasal dari PT. Sika Indonesia, yaitu sikament NN. Senyawa kimia pada sikament $\mathrm{NN}$ adalah napthtalene formaldehyde sulfonate dengan densitas 1,17 hingga $1,19 \mathrm{~kg} / \mathrm{l}$.

Tabel 2. Karakteristik Sodium Silikat

\begin{tabular}{ccc}
\hline Parameter uji & Satuan & Hasil analisis \\
\hline $\mathrm{SiO}_{2}$ & $\%$ & 31,75 \\
\hline $\mathrm{Na}_{2} \mathrm{O}$ & $\%$ & 14,51 \\
\hline Total solid & $\%$ & 46,26 \\
\hline Mol ratio & & 2,26 \\
\hline Density & $\mathrm{gr} / \mathrm{mL}$ & 1,56 \\
\hline Baume & $\mathrm{Be}$ & 52 \\
\hline
\end{tabular}

Air untuk campuran mortar merupakan air bersih (aquades) dari Pekanbaru dengan $\mathrm{pH}$ normal $(\mathrm{pH}=7)$ sesuai SNI 7974-2013 [23]. Air tersebut telah memenuhi standar air yang digunakan untuk membuat mortar.

\subsection{Perencanaan dan Studi Parametrik}

Studi parametrik dilakukan dengan menggunakan berbagai variasi parameter untuk mendapatkan komposisi optimum mortar geopolimer hybrid POFA yang dirawat di suhu ruang. Tabel 3 menunjukkan parameter untuk perencanaan campuran.
Tabel 3. Parameter Perencanaan Campuran

\begin{tabular}{ccccccc}
\hline Mix & Ms & $\begin{array}{c}\text { NaOH } \\
(\mathrm{M})\end{array}$ & $\begin{array}{c}\text { Suhu } \\
\left({ }^{\circ} \mathrm{C}\right)\end{array}$ & $\begin{array}{c}\text { Treatment } \\
\text { POFA }\end{array}$ & $\begin{array}{c}\text { Rest } \\
\text { Period } \\
(\text { hari })\end{array}$ & $\begin{array}{c}\text { PCC } \\
(\%)\end{array}$ \\
\hline 1 & 1 & 14 & 28 & Saring dan oven & 5 & 0 \\
\hline 2 & 2 & 14 & 28 & Saring dan oven & 5 & 0 \\
\hline 3 & 2,5 & 14 & 28 & Saring dan oven & 5 & 0 \\
\hline 4 & 3 & 14 & 28 & Saring dan oven & 5 & 0 \\
\hline 5 & 2,5 & 10 & 28 & Saring dan oven & 5 & 0 \\
\hline 6 & 2,5 & 12 & 28 & Saring dan oven & 5 & 0 \\
\hline 7 & 2,5 & 16 & 28 & Saring dan oven & 5 & 0 \\
\hline 8 & 2,5 & 14 & 60 & Saring dan oven & 5 & 0 \\
\hline 9 & 2,5 & 14 & 100 & Saring dan oven & 5 & 0 \\
\hline 10 & 2,5 & 14 & 28 & Furnace Tungku & 5 & 0 \\
\hline 11 & 2,5 & 14 & 28 & Furnace 800 ${ }^{\circ} \mathrm{C}$ & 5 & 0 \\
\hline 12 & 2,5 & 14 & 28 & Saring dan oven & 3 & 0 \\
\hline 13 & 2,5 & 14 & 28 & Saring dan oven & 5 & 5 \\
\hline 14 & 2,5 & 14 & 28 & Saring dan oven & 5 & 10 \\
\hline 15 & 2,5 & 14 & 28 & Saring dan oven & 5 & 15 \\
\hline
\end{tabular}

Parameter yang dikaji adalah modulus aktivator (perbandingan $\mathrm{Na}_{2} \mathrm{SiO}_{3} / \mathrm{NaOH}$ ), konsentrasi $\mathrm{NaOH}$, suhu perawatan, teknik persiapan geopolimer POFA, rest period dan persentase semen PCC. Studi parametrik menggunakan ketentuan apabila satu parameter dibuat bervariasi maka parameter lainnya akan bernilai tetap. Pada campuran 1, 2, 3 dan 4, dapat dilihat bahwa parameter yang berubah adalah $\mathrm{Ms}=1,2,2,5$ dan 3, sedangkan molaritas $\mathrm{NaOH}$, suhu perawatan, persiapan POFA, rest period dan persentase PCC tetap.

Pada studi parametrik ini, campuran no 3 digunakan sebagai campuran kontrol dengan rasio modulus aktivator $(\mathrm{Ms})=2,5$, molaritas $\mathrm{NaOH}$ $14 \mathrm{M}$, suhu curing $28^{\circ} \mathrm{C}$ (suhu ruang), POFA disaring dan di oven serta rest period 5 hari. Penetapan parameter kontrol ini berdasarkan hasil kajian literatur sebelumnya.

Komposisi campuran berdasarkan perhitungan parameter selengkapnya dapat dilihat pada Tabel 4. 
Tabel 4. Komposisi Campuran Mortar

\begin{tabular}{cccccccc}
\hline \multirow{2}{*}{$\begin{array}{c}\text { Trial } \\
\text { Mix }\end{array}$} & POFA & Pasir & $\mathrm{Air}$ & $\mathrm{Na}_{2} \mathrm{SiO}_{3}$ & $\mathrm{NaOH}$ & $\mathrm{SP}$ & $\mathrm{PCC}$ \\
\hline 1 & 321,85 & 1727,39 & 120 & 152,88 & 152,88 & 4,83 & 0,00 \\
\hline 2 & 321,85 & 1727,39 & 120 & 203,84 & 101,92 & 4,83 & 0,00 \\
\hline 3 & 321,85 & 1727,39 & 120 & 218,40 & 87,36 & 4,83 & 0,00 \\
\hline 4 & 321,85 & 1727,39 & 120 & 229,32 & 76,44 & 4,83 & 0,00 \\
\hline 5 & 321,85 & 1727,39 & 120 & 218,40 & 87,36 & 4,83 & 0,00 \\
\hline 6 & 321,85 & 1727,39 & 120 & 218,40 & 87,36 & 4,83 & 0,00 \\
\hline 7 & 321,85 & 1727,39 & 120 & 218,40 & 87,36 & 4,83 & 0,00 \\
\hline 8 & 321,85 & 1727,39 & 120 & 218,40 & 87,36 & 4,83 & 0,00 \\
\hline 9 & 321,85 & 1727,39 & 120 & 218,40 & 87,36 & 4,83 & 0,00 \\
\hline 10 & 321,85 & 1727,39 & 120 & 218,40 & 87,36 & 4,83 & 0,00 \\
\hline 11 & 321,85 & 1727,39 & 120 & 218,40 & 87,36 & 4,83 & 0,00 \\
\hline 12 & 321,85 & 1727,39 & 120 & 218,40 & 87,36 & 4,83 & 0,00 \\
\hline 13 & 305,76 & 1727,39 & 120 & 218,40 & 87,36 & 4,83 & 16,09 \\
\hline 14 & 289,67 & 1727,39 & 120 & 218,40 & 87,36 & 4,83 & 32,19 \\
\hline 15 & 273,57 & 1727,39 & 120 & 218,40 & 87,36 & 4,83 & 48,28 \\
\hline & & & & & & & \\
\hline
\end{tabular}

\subsection{Pembuatan dan Pengujian Benda Uji}

Benda uji dibuat melalu beberapa langkah yang dapat dilihat pada Gambar 1. Langkah pertama adalah mempersiapkan campuran POFA, pasir dan larutan alkali aktivator.

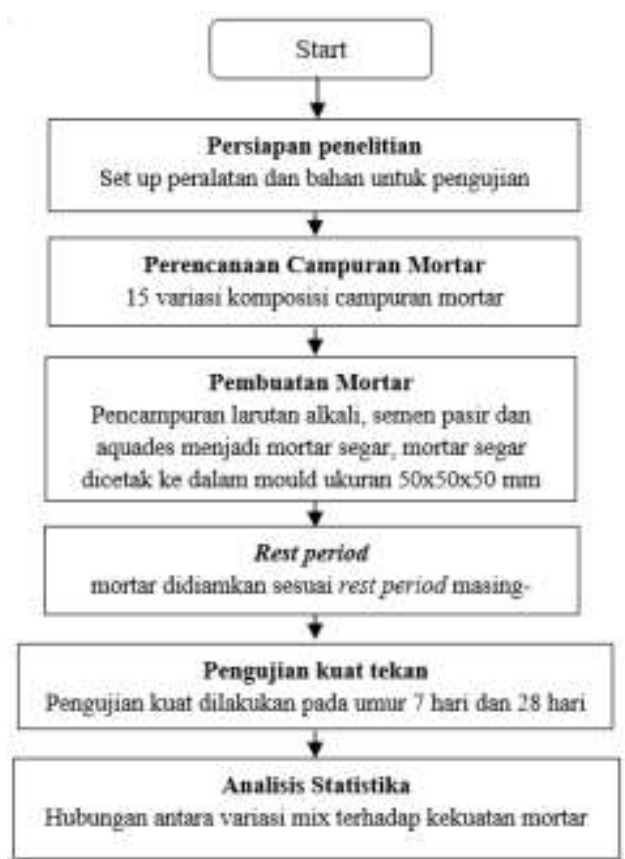

Gambar 1. Pembuatan dan pengujian sampel.
Larutan alkali aktivator disiapkan 2-3 jam sebelum pencampuran dilakukan. Proses pencampuran dilakukan secara manual. Abu sawit dan pasir diaduk terlebih dahulu hingga tercampur rata, kemudian dilanjutkan dengan penambahan larutan alkali aktivator sedikit demi sedikit ke dalam campuran POFA dan pasir, kemudian diaduk selama \pm 5 menit hingga seluruh bahan tercampur rata. Campuran mortar segar kemudian dimasukkan ke dalam cetakan. Campuran mortar kemudian didiamkan sesuai rest period masing-masing mix. Selanjutnya mortar dikeluarkan dari cetakan dan ditempatkan pada suhu ruang hingga hari pengujian kuat tekan. Pengujian kuat tekan dilakukan pada umur 7 hari dan 28 hari. Untuk tiap campuran dibuat tiga benda uji.

\section{HASIL DAN PEMBAHASAN}

\subsection{Uji Tekan Mortar}

\subsubsection{Pengaruh Modulus Aktivator (Ms)}

Pengaruh rasio modulus Aktivator (Ms) terhadap kuat tekan dapat dilihat pada Gambar 2. Secara umum, kuat tekan mortar pada mix 3 (Ms $=2,5$ ) mengalami peningkatan, sebelum akhirnya sedikit menurun pada mix $4(\mathrm{Ms}=3)$. Penelitian sebelumnya menunjukkan komposisi optimal pada campuran dapat meningkatkan kekuatan tekan [24]. Natrium silikat tidak hanya meningkatkan hasil akhir kuat tekan, namun juga merekatkan abu yang telah dilarutkan oleh $\mathrm{NaOH}$ dengan agregat. Peningkatan kuat tekan karena peningkatan jumlah larutan silikat dalam campuran juga dilaporkan oleh Hardjito et al. [20].

Pada mix 4 dengan modulus aktivator tertinggi $(\mathrm{Ms}=3)$, terjadi penurunan kuat tekan dibandingkan mix 3 dengan $\mathrm{Ms}=2,5$. Penurunan kuat tekan ini menunjukkan bahwa peningkatan jumlah larutan natrium silikat melebih jumlah optimal tidak memberikan pengaruh positif pada campuran mortar POFA. Penambahan natrium silikat dengan viskositas tinggi pada jumlah tertentu dapat memperbaiki ikatan geopolimer, tetapi dalam jumlah berlebihan menyebabkan campuran lebih lengket dan sulit dikerjakan. Hal ini telah dijelaskan oleh Shindunata et al. [25] bahwa kandungan natrium silikat tinggi dalam campuran akan menghasilkan geopolimer dengan porositas tinggi dan kekuatan rendah. 


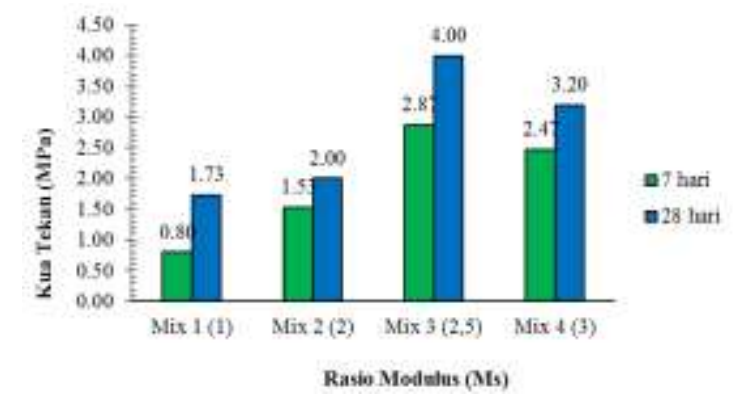

Gambar 2. Pengaruh Rasio Modulus Aktivator

\subsubsection{Pengaruh Molaritas $\mathrm{NaOH}$}

Gambar 3 memperlihatkan variasi kuat tekan akibat molaritas $\mathrm{NaOH}$. Kadar $\mathrm{NaOH}$ yang tepat akan sangat berpengaruh terhadap hasil kekuatan mortar [15]. Semakin tinggi molaritas larutan, maka $\mathrm{NaOH}$ dalam campuran akan semakin pekat. Pada umumnya semakin pekat atau tinggi molaritas $\mathrm{NaOH}$ akan semakin tinggi kuat tekan. Pada Gambar 3 dapat dilihat peningkatan kekuatan pada mix $3(14 \mathrm{M})$ sebelum akhirnya menurun pada mix 7 (16 M). Campuran menggunakan $\mathrm{NaOH} 16 \mathrm{M}$ memiliki kuat tekan lebih rendah dibandingkan $\mathrm{NaOH}$. Hal ini terjadi karena larutan alkali aktivator mengalami pengerasan lebih cepat (mengkristal) saat semua bahan dicampur sehingga mengurangi homogenitas larutan, volume larutan, kemudahpengerjaan larutan dan kuat tekan beton dihasilkan.

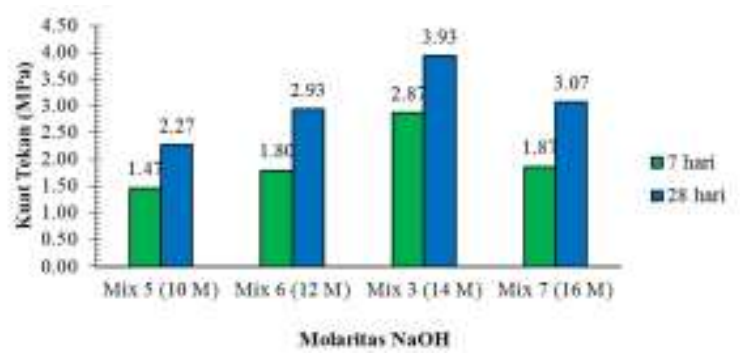

Gambar 3. Pengaruh Molaritas $\mathrm{NaOH}$

Penambahan jumlah $\mathrm{NaOH}$ dalam campuran akan membutuhkan lebih banyak larutan silikat agar proporsi campuran geopolimer seimbang. Ketidakseimbangan proporsi larutan kimia mengurangi menyebabkan campuran menjadi lengket dan sulit untuk dipadatkan [26]. Penambahan molaritas larutan $\mathrm{NaOH}$ tidak selalu diiringi dengan peningkatan kuat tekan mortar.

\subsubsection{Pengaruh Suhu Perawatan (Curing)}

Hasil kuat tekan mortar geopolimer POFA berdasarkan variasi suhu curing ditunjukkan pada Gambar 4.

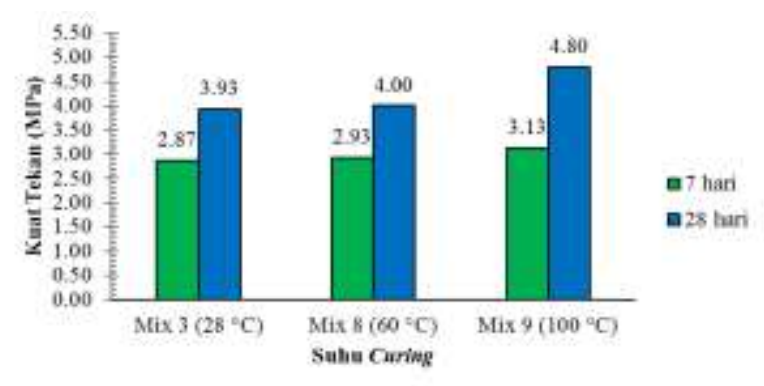

Gambar 4. Pengaruh Suhu Perawatan

Pada Gambar 4 dapat dilihat bahwa mix 9 dengan suhu curing $100^{\circ} \mathrm{C}$ menghasilkan kuat tekan mortar tertinggi. Pada umumnya, semakin tinggi suhu curing maka semakin tinggi kuat tekan karena pada suhu ruang reaksi geopolimer berjalan sangat lambat. Kandungan alumina $\left(\mathrm{Al}_{2} \mathrm{O}_{3}\right)$ pada POFA yang cukup rendah, yaitu sebesar 13,87\% menjadi salah satu faktor POFA kurang reaktif sehingga memerlukan suhu curing lebih tinggi untuk mempercepat reaksi kimia saat proses geopolimerisasi. Pemberian suhu tinggi akan mempercepat terjadinya reaksi kimia dan meningkatkan kuat tekan mortar [27].

\subsubsection{Pengaruh Rest Period}

Gambar 5 menunjukkan pengaruh rest period pada kuat tekan mortar hybrid geopolimer.

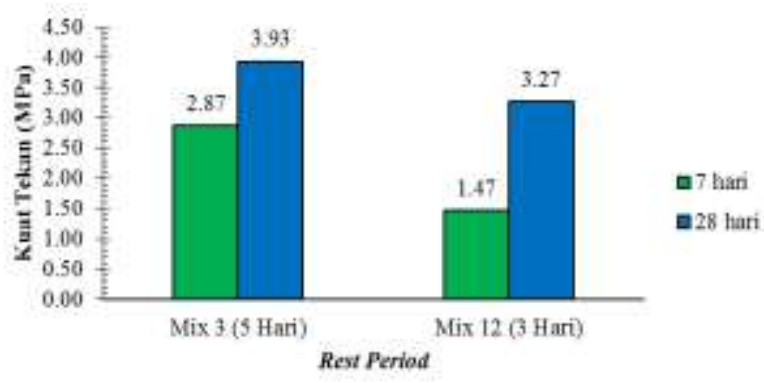

Gambar 5. Pengaruh Rest Period

Mix 3 yang dirawat dengan rest period selama 5 hari menunjukkan kuat tekan lebih tinggi daripada benda uji dengan rest period selama 3 hari. Penelitian Hardjito [20] menunjukkan hasil serupa. Peningkatan waktu rest period akan menghasilkan kuat tekan lebih tinggi, meski peningkatan kekuatan hingga umur 28 hari tidak terlalu signifikan.

\subsubsection{Pengaruh Treatment POFA}

Partikel POFA tidak reaktif karena memiliki kandungan karbon tinggi dengan warna gelap. Partikel perlu diolah kembali seperti 
dibakar ulang atau dihaluskan agar kualitas geopolimer hybrid yang dihasilkan lebih baik. Penelitian sebelumnya menunjukkan bahwa partikel POFA yang dibakar selama 1,5 jam pada suhu $500 \pm 50^{\circ} \mathrm{C}$ dapat mengurangi kandungan karbon dalam abu sawit [28]. Karbon yang tidak terbakar menghasilkan geopolimer POFA rapuh, keropos dan berkekuatan rendah.

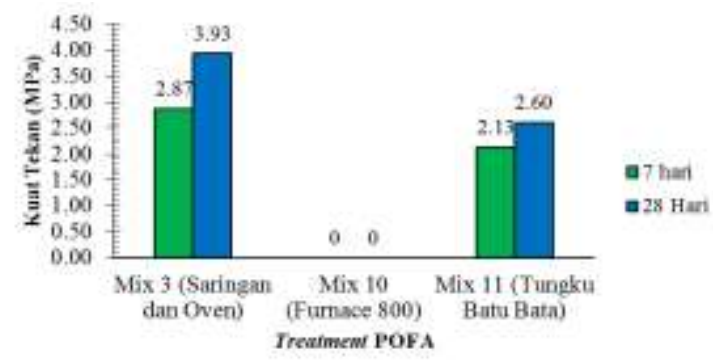

Gambar 6. Pengaruh Treatment POFA

Pada Gambar 6 dapat dilihat bahwa mortar geopolimer POFA dengan partikel yang disaring menggunakan ayakan No. 200 dan dirawat pada suhu tinggi memiliki kekuatan lebih tinggi dibandingkan dengan mix 11 dengan partikel POFA dibakar pada tungku batu bata selama 3 hari. Mix 10 dengan partikel POFA dibakar dalam furnace bata dengan suhu $800^{\circ} \mathrm{C}$ selama 1 jam tidak memiliki ikatan baik sehingga rapuh dan mudah pecah saat cetakan dibuka. Seharusnya kuat tekan mix 10 lebih baik karena kandungan karbon pada abu berkurang setelah dibakar pada suhu tinggi. Akan tetapi, senyawa-senyawa penting dalam POFA, seperti $\mathrm{SiO}_{2}$ dapat terurai dalam suhu lebih dari $500^{\circ} \mathrm{C}$ sehingga reaksi dan ikatan geopolimerisasi tidak terjadi. Pengeringan POFA dengan suhu sangat tinggi tidak direkomendasikan untuk bahan geopolimer.

\subsubsection{Pengaruh Penggantian PCC}

Pada Gambar 7 dapat dilihat pengaruh penggantian sejumlah volume POFA dengan PCC terhadap kuat tekan mortar hybrid geopolimer POFA.

Semakin tinggi pergantian PPC terhadap POFA maka semakin baik kuat tekan yang diperoleh. Penambahan semen PCC berfungsi untuk merekatkan butiran pasir dan juga mempercepat reaksi geopolimer dengan energi panas (hidrasi) yang dihasilkan oleh semen, sehingga perawatannya cukup dilakukan menggunakan suhu ruang [29]. Kondisi ini memungkinkan geopolimer hybrid dapat diaplikasikan dengan praktis tanpa memerlukan suhu perawatan yang tinggi.

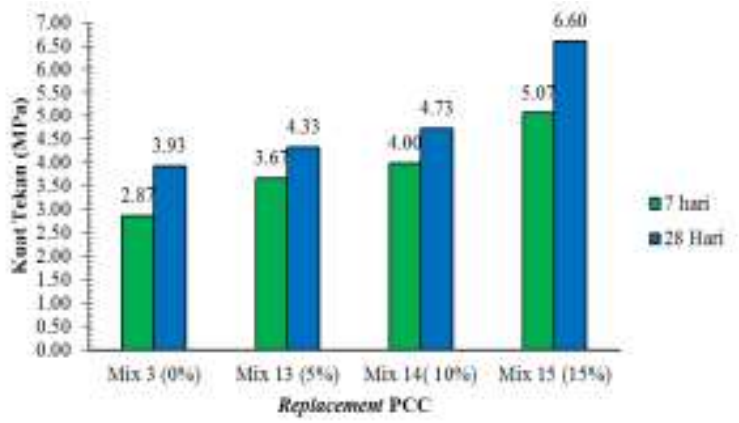

Gambar 7. Pengaruh Replacement PCC

\section{KESIMPULAN}

Pada penelitian ini telah dilakukan studi parametrik untuk mendapatkan komposisi optimum mortar geopolimer hybrid POFA menggunakan variasi modulus aktivator, dosis $\mathrm{NaOH}$, suhu perawatan, rest period dan perlakuan partikel POFA. Hasil penelitian menunjukkan bahwa campuran optimum mortar geopolimer hybrid POFA adalah campuran dengan $\mathrm{NaOH}$ $14 \mathrm{M}$, rasio $\mathrm{Ms}=2,5$, suhu perawatan $100^{\circ} \mathrm{C}$, rest period selama 5 hari, partikel POFA dikeringkan dalam oven dan disaring dengan saringan \#200, dan kandungan PCC sebesar 15\%. Mortar geopolimer dengan campuran optimum tersebut menghasilkan kuat tekan tertinggi sebesar 6,6 MPa pada umur 28 hari.

\section{UCAPAN TERIMAKASIH}

Penelitian ini didanai melalui kegiatan PKM-Penelitian, Program Kreativitas Mahasiswa, Direktorat Jenderal Pembelajaran dan Kemahasiswaan Kementerian Riset, Teknologi, dan Pendidikan Tinggi tahun 2019.

\section{DAFTAR PUSTAKA}

[1] Laporan Tahunan PT Semen Indonesia (Persero) Tbk. Accelerated Transformation, Jakarta, 2018.

[2] Canpolat, B.R., Atimtay, A.T., Munlafalioglu, I., Kalafatoglu, E., dan Ekinci, E., 2001. Emission Factor of Cement Industry in Turkey. Istanbul, Water, Air and Soil Pollution, Vol 138, 2002: 235-252.

[3] Davidovits, J., Properties of Geopolymer Cements, Materials Science, Vol 16, 1994: 1-19

[4] Miranda, J.M., Fernandez-Jimenez, A., Gonzalez J.A, dan Palomo A, Corrosion Resistance in Activated Fly Ash Mortars, Cement and Concrete Research, Vol 35, 2006: 1210-1217. 
[5] Direktorat Jenderal Perkebunan. Statistik Perkebunan Indonesia, Kelapa Sawit, 2016-2018, 2018

[6] Farandia, R.Y., Olivia, M., dan Darmayanti, L., Kinerja Beton High Volume Pofa, Jurnal Online Mahasiswa Fakultas Teknik, Vol 1, 2014: 1-12.

[7] Tangchirapat, W., Jaturapitakkul, C., dan P. Chindaprasirt, P., Use of Palm Oil Fuel Ash as a Supplementary Cementitious Material for Producing High-strength Concrete. Construction and Building Materials, Vol 23, 2009: 2641-2646.

[8] Olivia, M., Tambunan, L.M, dan Saputra, E., Properties of Palm Oil Fuel Ash (POFA) Geopolymer Mortar Cured at Ambient Temperature, Matec Web of Conference, Vol 97, 2017: 01006

[9] SNI 03-6825-2002, Metode Pengujian Kekuatan Tekan Mortar Semen Portland untuk Pekerjaan Sipil, Jakarta, 2002.

[10] SNI 6882-2014, Spesifikasi mortar untuk pekerjaan unit pasangan, Jakarta, 2014.

[11] Davidovits, J., High-Alkali Cements for 21st Century Concretes, Materials Science, Vol 144, 1994: 383-398

[12] Rangan, B.V., Hardjito, D., Wallah, S.E., dan Sumajouw, D.M.J., Studies on Engineering Properties of Fly Ash-Based Geopolymer Concrete, in Davidovits, J. (ed), Geopolymer, Green Chemistry and Sustainable Development, St Quentin, 2005.

[13] Adam, A. Strength and Durability Properties of Alkali Activated Slag and Fly Ash-Based Geopolymer Concrete, PhD Thesis RMIT University, Melbourne, 2009.

[14] Fernandez-Jimenez, A., Palomo, A., dan Criado, M. Microstructure Development of Alkali-Activated Fly Ash Cement: A Descriptive Model, Cement and Concrete Research, Vol 35 , 2005: 1204-1209.

[15] Olivia, M., Geopolimer sebagai Material Infrastruktur Berkelanjutan di Lingkungan Gambut, Prosiding Annual Civil Engineering Seminar, Pekanbaru, 2015.

[16] Mulia., Pemanfaatan Tandan Kosong dan Cangkang Kelapa Sawit Sebagai Briket Arang, Tesis Magister Teknik Kimia, 2007.

[17] ASTM C-618 2005, Standard Specification for Coal Fly Ash and Raw or Calcined Natural Pozzolan for Use, West Conshohocken, 2005.

[18] SNI 15-2049-2004. Semen Portland, Jakarta,
2004

[19] Kasyanto, H., Tinjauan Kuat Tekan Geopolimer Berbahan Dasar Fly Ash dengan Aktivator Sodium Hidroksida dan Sodium Silikat, Industrial Researcher Workshop and National Seminar, 2012.

[20] Hardjito, D, Wallah, S.E., Sumajouw, D.M.J., dan Rangan, B.V., On the Development of Fly Ash-Based Geopolymer Concrete. ACI Materials Journal, Vol 101, 2004: 467-472.

[21] Utami, R. I. A., dan Herbudiman, B., Efek Tipe Superplasticizer Terhadap Sifat Beton Segar dan Beton Keras pada Beton Geopolimer Berbasis Fly Ash, Jurnal Online Institut Teknologi Nasional, Vol 3, 2017: 1-12

[22] SNI 03-1968-1990, Metode Pengujian Tentang Analisis Saringan Agregat Halus dan Kasar, Jakarta, 1990.

[23] SNI 7974-2013, Spesifikasi Air Pencampur yang Digunakan dalam Produksi Beton Semen Hidraulis, Jakarta, 2013.

[24] Steveson, M. dan Sagoe-Crentsil, K., Relationships Between Composition, Structure and Strength of Inorganic Polymers, Journal of Materials Science, Vol 40, 2005: 2023-2036.

[25] Shindunata, van Deventer, J.S.J., Lukey, G.C., $\mathrm{Xu}, \mathrm{H}$., Effect of curing temperature and silicate concentration on fly ash based geopolymerization, Industrial \& Engineering Chemistry Res., Vol. 45, 2006: 3559-3568.

[26] Sindhunata, Provis, J.L., Lukey, G.C., Xu, H., and van Deventer, J.S.J., Structural Evolution of Fly Ash Based Geopolymers in Alkaline Environments, Industrial \& Engineering Chemistry Research, Vol 47, 2008: 2991-2999.

[27] Rangan, B.V., Hardjito, D., Wallah, S.E., \& Sumajouw, D.M.J., Fly Ash Based Geopolymer Concrete: A Construction Material For Sustainable Development, Australian Journal of Structural Engineering, Vol 31, 2005: 25-30.

[28] Johari, M., A., M., Zeyad, A., M., Bunnori N., M., dan Ariffin, K., S., Properties of High-Strength Green Concrete Containing High Volume of Ultrafine Palm Oil Fuel Ash, Construction and Building Materials, Vol 30, 2012: 281-288.

[32] Salih, M.A., Ali, A.A.A., dan Farzadnia, N., Characterization of Mechanical and Microstructural Properties of Palm Oil Fuel Ash Geopolymer Cement Paste, Construction and Building Materials, Vol 65, 2014: 592-603. 